\title{
REGULARITY FOR SOLUTIONS OF NONLINEAR RETARDED FUNCTIONAL DIFFERENTIAL EQUATIONS
}

\author{
Jin-Mun JEONG AND SANG-Jin Son
}

Abstract. This paper deals with the existence and uniqueness of solutions for the nonlinear functional differential equations with time delay. The regularity and a variation of constant formula for solutions of the given equations are also studied.

Mathematics subject classification (2010): 35F25, 35K55.

Keywords and phrases: Nonlinear differential equation, monotone operator, existence, regularity.

\section{REFERENCES}

[1] N. U. AHMED AND X. XIANG, Existence of solutions for a class of nonlinear evolution equations with nonmonotone perturbations, Nonlinear Analysis, T. M. A. 22, 1 (1994), 81-89.

[2] J. P. Aubin, Un thèorémede compasité, C. R. Acad. Sci. 256, (1963), 5042-5044.

[3] V. BARBU, Nonlinear Semigroups and Differential Equations in Banach space, Nordhoff Leiden, Netherlands, 1976.

[4] H. BRÉZIS, Opérateurs Maximaux Monotones et Semigroupes de Contractions dans un Espace de Hilbert, North Holland, 1973.

[5] N. HiRAno, Nonlinear evolution equations with nonmonotonic perturbations, Nonlinear Analysis, T. M. A. 13, 6 (1989), 599-609.

[6] J. M. JEOnG, Y. C. KWUn AND J. Y. PARK, Approximate controllability for semilinear retarded functional differential equations, J. Dynamics and Control Systems, 5, 3 (1999), 329-346.

[7] I. I. VRABIE, An existence result for a class of nonlinear evolution equations in Banach spaces, Nonlinear Analysis, T. M. A. 7, (1982), 711-722.

[8] J. Yong AND L. PAn, Quasi-linear parabolic partial differential equations with delays in the highest order partial derivatives, J. Austral. Math. Soc. 54, (1993), 174-203. 